\title{
miR-671-5p inhibits gastric cancer cell proliferation and promotes cell apoptosis by targeting URGCP
}

\author{
TIEFENG QIU $^{1 *}$, KEPING WANG ${ }^{2 *}$, XIANWEN LI $^{3}$ and JIANHUA JIN ${ }^{3}$ \\ ${ }^{1}$ Department of Respiratory Medicine, Wujin Hospital Affiliated to Jiangsu University, Changzhou, Jiangsu 213002; \\ ${ }^{2}$ Department of Thoracic Surgery, Chest Hospital of Nanjing, Nanjing, Jiangsu 210029; ${ }^{3}$ Department of Medical Oncology, \\ Wujin Hospital Affiliated to Jiangsu University, Changzhou, Jiangsu 213002, P.R. China
}

Received April 26, 2017; Accepted August 24, 2017

DOI: $10.3892 /$ etm.2018.6813

\begin{abstract}
Various studies have demonstrated that microRNA (miRNA) serves an important role in the development of gastric cancer. However, the expression level, clinical significance and the biological function of miRNA in gastric cancer remain largely unknown. The present study investigated the exact roles of miR-671-5p in gastric cancer, confirmed its target and explored its mechanism. Initially, the low expression levels of miR-671-5p in gastric cancer cells were confirmed by reverse transcription-quantitative polymerase chain reaction. TargetScan and MiRanda databases were utilized to forecast the target genes of miR-671-5p, and the prediction was verified by dual-luciferase reporter assay and western blot analysis. Cell Counting Kit-8 was used for cell proliferation detection. An annexin V-fluorescein isothiocyanate kit was used for cell apoptosis determination. Western blot analysis was adopted to measure the protein expression levels in different groups. The results of the present study revealed that there were lower expression levels of miR-671-5p in gastric cancer cells than in normal gastric cells. Upregulator of cell proliferation (URGCP) is a direct target of miR-671-5p and it may be negatively regulated by miR-671-5p. miR-671-5p mimics induced reduction of MKN28 cell proliferation. miR-671-5p mimics caused upregulation of MKN28 cell apoptosis. In addition, western blotting results indicated that the ratio of B-cell lymphoma 2 (Bcl-2)/Bcl-2-associated X protein was significantly decreased in the miR-671-5p mimic group compared with the negative control group $(\mathrm{P}<0.01)$. These results suggested that miR-671-5p had a protective role in gastric cancer through inhibiting gastric cancer cell proliferation and promoting cell
\end{abstract}

Correspondence to: Dr Xianwen Li, Department of Medical Oncology, Wujin Hospital Affiliated to Jiangsu University, 2 Yongning North Road, Changzhou, Jiangsu 213002, P.R. China E-mail: xianwenli123@126.com

\section{*Contributed equally}

Key words: microRNA-671-5p, upregulator of cell proliferation, proliferation, apoptosis, target apoptosis by targeting URGCP. Therefore, miR-671-5p may be an effective therapeutic target for gastric cancer.

\section{Introduction}

Gastric cancer, one of the most common types of gastrointestinal cancer in China and a major cause of cancer-related mortality worldwide, is a serious threat to health (1-3). Unhealthy eating habits, smoking, alcohol, viruses and bacteria are risk factors for gastric cancer (4). Due to poor diagnosis, many patients are diagnosed with advanced gastric cancer characterized by extensive invasion and lymphatic metastasis $(5,6)$. Comprehensive treatment with surgery, chemotherapy and radiotherapy remains the only effective therapy for gastric cancer (7). Although many improvements have been made in the treatment of gastric cancer, the overall survival of patients with gastric cancer is very low, and the prognosis for patients is not so optimistic (8). Currently, the traditional drug therapy for tumors generally refers to chemotherapy; however, normal and malignant cells are destroyed by chemotherapy, leading to great toxicity to patients (9). Molecular targeted therapy has limited or nonexistent side effects on normal cells of the body (10). Thus, it is of great importance to identify novel and effective therapeutic targets for gastric cancer.

MicroRNA (miRNA), a group of small non-coding RNA, are able to regulate the expression of downstream targets by binding to the 3 '-untranslated region of the target (UTR) genes $(11,12)$. Evidence has strongly indicated that miRNA serve essential roles in the regulation of a variety of biological progresses, including cell proliferation, apoptosis, invasion and migration (13). Additionally, various studies have demonstrated that miRNA have an important role in gastric cancer progression (14-17).

Upregulator of cell proliferation (URGCP)/upregulated gene 4 (URG4) is upregulated in a variety of human cancer types, including hepatocellular carcinoma, epithelial ovarian cancer, osteosarcoma and gastric cancer (18). URGCP is a tumor promoter, which has been reported to serve critical roles in gastric cancer cell proliferation (19-22). TargetScan and MiRanda database results have suggested that the 3'UTR of URGCP contains the complementary sequence of miR-671-5p (23). 
Previous research has demonstrated that miR-671 was significantly downregulated in gastric cancer cells compared with normal gastric cells (24). Bioinformatic analyses have suggested that the predicted targets of URGCP were associated with the cell cycle, cell adhesion, apoptosis, transcription and gene expression (25). As the precise expression and roles of miR-671-5p in gastric cancer have not been fully elucidated, the present study aimed to investigate the roles of miR-671-5p in gastric cancer and explore its mechanism.

\section{Materials and methods}

Tissues and cell lines. Fresh gastric cancer tissues and its corresponding para-carcinoma tissues were obtained from Wujin Hospital affiliated to Jiangsu University (Changzhou, China). The tissues were provided by 30 patients with gastric cancer (mean age, 51.2 years; 19 males and 11 females) between January 2014 and January 2016. The present study was approved the Ethics Committee of Wujin Hospital affiliated to Jiangsu University. Patients provided written informed consent prior to initiation of the study. According to the seventh edition of TNM classification for gastric cancer (26), $2(6.7 \%)$ patients were Ia stage, $3(10 \%)$ patients were IIa stage, $3(10 \%)$ patients were IIb stage, $10(33.3 \%)$ were IIIa and $12(40 \%)$ were stage IIIc. All tissues were immediately snap-frozen in liquid nitrogen following surgery.

Gastric cancer cells (MKN28), normal gastric cells (HFE145) and 293T cells were purchased from Shanghai Bogoo Biotechnology Co., Ltd., (Shanghai, China). According to research, the MKN28 cell line is a derivative of the MKN74 gastric tubular adenocarcinoma cell line (27). MKN28 cells were routinely grown in RPMI-1640 medium supplemented with $10 \%$ fetal bovine serum (both, Shanghai BioSun Science $\&$ Technology Co., Ltd., Shanghai, China), $1 \%$ penicillin and streptomycin combination at $37^{\circ} \mathrm{C}$ in a humidified atmosphere with $5 \% \mathrm{CO}_{2}$. HFE145 and $293 \mathrm{~T}$ cells were cultured in Dulbecco's modified Eagle's medium supplemented with $10 \%$ fetal bovine serum (Shanghai BioSun Science \& Technology Co., Ltd.) at $37^{\circ} \mathrm{C}$ with $5 \% \mathrm{CO}_{2}$.

miR-671-5p target prediction. TargetScan (targetscan. org/vert_71) and MiRanda databases (mirbase.org) were employed for miR-671-5p target prediction.

Cell transfection. A total of $24 \mathrm{~h}$ prior to transfection, MKN28 cells $\left(9.5 \times 10^{5} /\right.$ well) were seeded in a 6 -well plate. Following this, the cells were transfected with miR-671-5p mimic $(2.5 \mu \mathrm{g})$ or mimic control (cat. no. HMC0002; Sigma-Aldrich; Merck KGaA, Darmstadt, Germany) by using Lipofectamine 2000 reagent (10 $\mu \mathrm{l}$; Invitrogen; Thermo Fisher Scientific, Inc., Waltham, MA, USA) following the manufacturer's protocol. The sequence of the miR-671-5p mimic used was 5'-AGG AAGCCCUGGAGGGGCUGGAG-3' (cat. no. HMI0901; Sigma-Aldrich; Merck KGaA). The plasmids were purchased from Shanghai Kaiyang Biotechnology Co., Ltd., (Shanghai, China). A total of $24 \mathrm{~h}$ after transfection, cell samples were collected for further analysis.

Cell proliferation assay. MKN28 cell proliferation ability was detected using a Cell Counting Kit-8 (CCK-8; Dojindo
Molecular Technologies, Inc., Kumamoto, Japan) according to the manufacturer's protocol. At $24 \mathrm{~h}$ post-transfection with miR-671-5p mimic or mimic control, MKN28 cells were seeded into a $96-$ well plate $\left(3 \times 10^{3}\right.$ cells/well). Subsequently, $20 \mu \mathrm{l} \mathrm{CCK}-8(5 \mathrm{mg} / \mathrm{ml})$ was added to each well and incubated at $37^{\circ} \mathrm{C}$ for $4 \mathrm{~h}$. A spectrophotometer was utilized to determine the optical densities (OD) at $490 \mathrm{~nm}$ at 24, 48 and $72 \mathrm{~h}$, respectively. The proliferation rate was determined at $72 \mathrm{~h}$ after transfection. All experiments were performed in triplicate.

Apoptosis analysis assay. To detect cell apoptosis levels, a fluorescein isothiocyanate (FITC) apoptosis detection kit (Vazyme, Piscataway, NJ, USA) was utilized, following the manufacturer's protocol. A total of $24 \mathrm{~h}$ after transfection, MKN28 cells were washed three times with cold PBS solution. Subsequently, MKN28 cells were re-suspended in 1X binding buffer solution, stained with annexin V-FITC and propidium iodide, and then incubated for $15 \mathrm{~min}$ at room temperature in the dark. A flow cytometer (BD Biosciences, Franklin Lakes, NJ, USA) was used to detect the cell apoptotic rate using WinMDI version 2.5 (Purdue University Cytometry Laboratories, West Lafayette, IN, USA). Tests were repeated three times.

Western blot analysis. Western blot analysis was performed for protein expression detection according to standard procedures. The collected cells were lysed by a radioimmunoprecipitation buffer (cat. no. P0013B; Beyotime Institute of Biotechnology, Haimen, China) and then centrifuged at $11,180 \mathrm{x} \mathrm{g}$ for $15 \mathrm{~min}$ at $4^{\circ} \mathrm{C}$. The protein concentration was determined using a BCA kit. Protein samples (2 $\mu \mathrm{g} /$ lane) were electrophoresed by $12 \%$ SDS-PAGE and transferred onto polyvinylidene difluoride membranes (EMD Millipore, Billerica, MA, USA), then blocked in 5\% skimmed milk (cat. no. 232100; BD Biosciences) for $1 \mathrm{~h}$ at room temperature. Subsequently, membranes were blotted for $1 \mathrm{~h}$ at room temperature with antibodies directed against the following: URGCP (cat. no. HPA029468; 1.200; Sigma-Aldrich; Merck KGaA), GAPDH (cat. no. D16H11; 1:1,000; Cell Signaling Technology, Inc., Danvers, MA, USA), B-cell lymphoma 2 (Bcl-2; cat. no. KF364; 1:500; Nanjing Jiancheng Bioengineering Institute, Jiangsu, China) and Bcl-2-associated X protein (Bax; cat. no. PR-1381; 1:500; Jiangsu Sinogene Biotechnology Co., Ltd., Jiangsu, China) Following this, the membranes were incubated with horseradish peroxidase-labeled secondary antibodies (cat. no. 58802; 1:1,000; Cell Signaling Technology, Inc.) for $45 \mathrm{~min}$ at room temperature. The membranes were stained using an electrochemiluminescence kit (cat. no. 32209; Suzhou Biotsith Bioscience Co., Ltd., Suzhou, China) according to the manufacturer's protocol. Protein brands were then analyzed by ImageJ version 1.49 software (National Institute of Health, Bethesda, MD, USA).

RNA extraction and reverse transcription-quantitative polymerase chain reaction $(R T-q P C R)$. Total RNA from cultured cells was extracted using TRIzol reagent (Invitrogen; Thermo Fisher Scientific, Inc.) following the manufacturer's protocol. RT reactions were performed to synthesize cDNA by using a TaqMan miRNA RT kit (cat. no. 4366596FG; Shbybio 
A

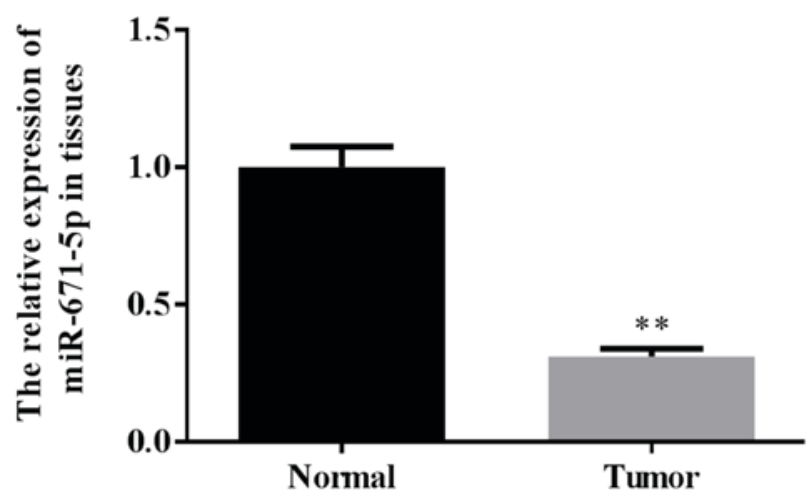

B

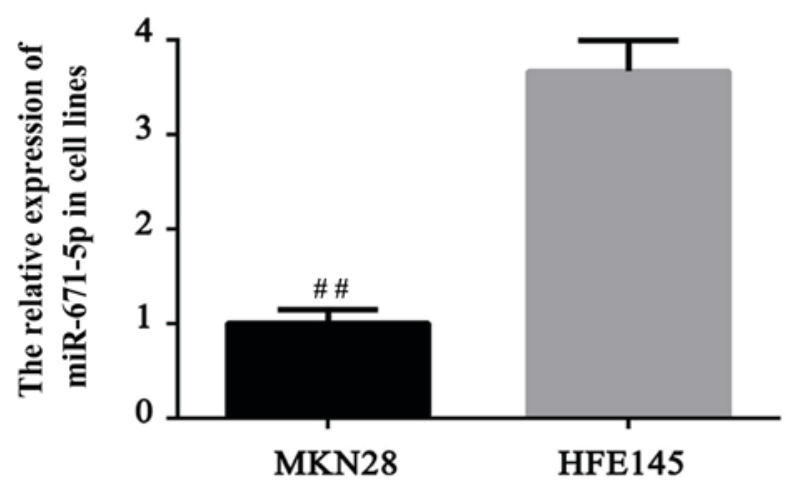

Figure 1. miR-671-5p expression is reduced in gastric cancer tissues and cell lines compared with normal gastric tissue and cell lines. The relative expression level of miR-671-5p in gastric cancer cells was measured by reverse transcription-quantitative polymerase chain reaction. (A) Relative expression level of miR-671-5p in gastric tumor and para-carcinoma tissues. (B) Relative expression of miR-671-5p in gastric cancer MKN28 cells and normal gastric HFE145 cells. ${ }^{* *} \mathrm{P}<0.01$ vs. normal tissue; ${ }^{\# \#} \mathrm{P}<0.01$ vs. HFE145 cells. miR, microRNA.

Co., Ltd., Shanghai, China) according to manufacturer's protocol. qPCR was subsequently performed using a QuantiTect SYBR-Green PCR kit (Qiagen, Inc., Valencia, CA, USA), in line with the manufacturer's protocol. U6 (for miRNA) was used as an internal control. The thermocycling conditions were $96^{\circ} \mathrm{C}$ for $5 \mathrm{~min}$ (pre-denaturation), $95^{\circ} \mathrm{C}$ for $30 \mathrm{sec}$ (initiation), $60^{\circ} \mathrm{C}$ for $30 \mathrm{sec}$ (annealing) and $76^{\circ} \mathrm{C}$ for $1.5 \mathrm{~min}$ (elongation), for a total of 32 cycles. Following this the samples were stored at $4^{\circ} \mathrm{C}$. The sequences of the primers used were as follows: Bcl-2 forward, 5'-GTCTTCGCTGCGGAGATCAT-3' and reverse, 3'-CAT TCCGATATACGCTGGGAC-5'; Bax forward, 5'-CCCGAG AGGTCTTTTTCCGAG-3' and reverse, 3'-CCAGCCCATGAT GGTTCTGAT-5'; URGCP forward, 5'-GACCTTGCTGCC GACATTTAT-3' and reverse, 3'-GCAGGAAACTGTCTGAGG AGAG-5'; and U6 forward 5'-AGTAAGCCCTTGCTGTCA GTG-3' and reverse 3'-CCTGGGTCTGATAATGCTGGG-5'. The MystiCq microRNA qPCR Assay Primers were used as the primers for miR-651-5p (cat. no. MIRAP00664-250RXN; Sigma-Aldrich; Merck KGaA). In addition, the relative expression of miR-671-5p and mRNA was quantified using the $2^{-\Delta \Delta \mathrm{Cq}}$ method (28). Tests were performed in triplicate.

Dual-luciferase reporter assay. Wild-type and mutant 3'UTR of URGCP were amplified and then cloned into the psiCHECK-2 reporter (cat. no. C8021; Promega Corporation, Madison, WI, USA). miR-671-5p and miR-671-5p-URGCP-wild type (WT) 3'UTR or miR-671-5p-URGCP-mutant (MUT) 3'UTR vectors were co-transfected into $293 \mathrm{~T}$ cells with $30 \mu \mathrm{l}$ Lipofectamine 2000 reagent according to the manufacturer's protocol. A total of $48 \mathrm{~h}$ after transfection, the dual-luciferase reporter assay system (Promega Corporation) was utilized to measure the luciferase activity. The luciferase activity was then normalized to the Renilla luciferase activity, which was used as the internal control.

Statistical analysis. Data were expressed as the mean \pm standard deviation. All statistical analyses were performed using SPSS 17.0 (SPSS, Inc., Chicago, IL, USA). A Student's t-test was performed to assess the difference between groups. $\mathrm{P}<0.05$ was considered to indicate a statistically significant difference.

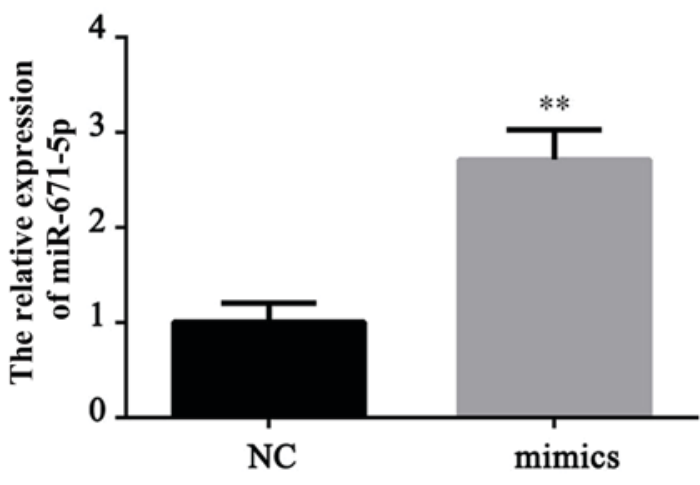

Figure 2. miR-671-5p mimic increased expression of miR-671-5p in MNK28 cells. The relative expression of miR-671-5p in the NC and mimic groups was measured by reverse transcription-quantitative polymerase chain reaction. ${ }^{* *} \mathrm{P}<0.01$ vs. NC. Tests were performed in triplicate. miR, microRNA; NC, negative control.

\section{Results}

Reduced expression of miR-671-5p in gastric cancer tissues and cells. The expression level of miR-671-5p in gastric cancer tissues and cells was determined. The expression level of miR-671-5p in tumor and normal gastric tissues, as well as gastric cancer MKN28 cells and the normal gastric HFE145 cells was detected using RT-qPCR. As demonstrated in Fig. 1A, the miR-671-5p expression level was significantly decreased in gastric tumor tissues compared with the levels in para-carcinoma (normal) tissues $(\mathrm{P}<0.01)$. Additionally, as indicated in Fig. 1B, a significant decrease of miR-671-5p expression was observed in gastric cancer MKN28 cells compared with the level in normal gastric HFE145 cells $(\mathrm{P}<0.01)$.

miR-671-5p mimic increases the expression level of $m i R-671-5 p$. To investigate the role of miR-671-5p in gastric cancer, a miR-671-5p overexpression cell line was established by transfection with miR-671-5p mimics. The effective upregulation of miR-671-5p was demonstrated by RT-qPCR (Fig. 2). The miR-671-5p mimic induced a significant increase 
A

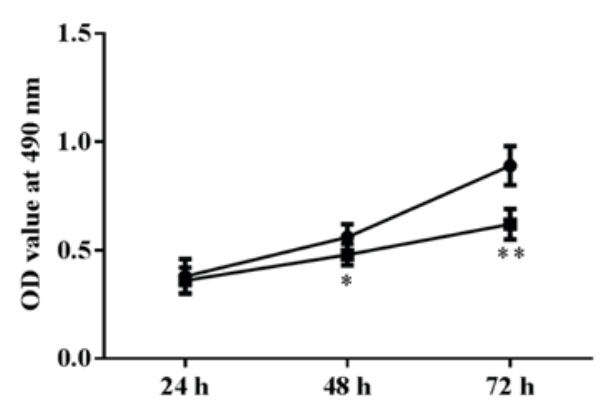

B

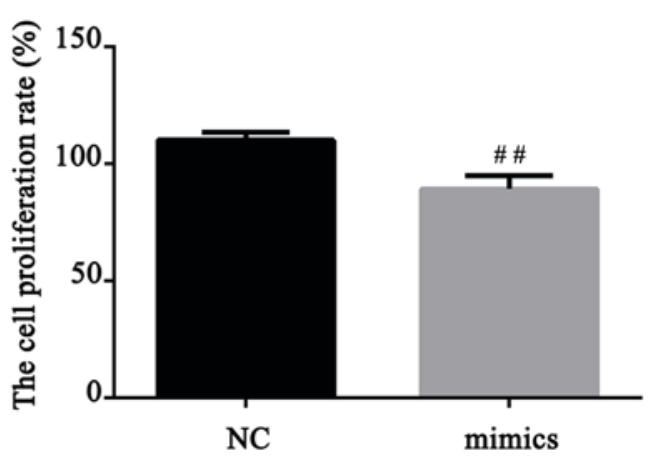

Figure 3. miR-671-5p inhibits gastric cancer cell proliferation. A total of $24 \mathrm{~h}$ after MKN28 cells were transfected with miR-671-5p mimics or its NC, a Cell Counting Kit-8 assay was used to detect cell proliferation. (A) OD value under $490 \mathrm{~nm}$ at 24,48 and $72 \mathrm{~h}$ after transfection. (B) Cell proliferation rate at $72 \mathrm{~h}$ after transfection. ${ }^{*} \mathrm{P}<0.05$ and ${ }^{* *} \mathrm{P}<0.01$ vs. NC at the same time point; ${ }^{\# \#} \mathrm{P}<0.01$ vs. NC. Tests were performed in triplicate. miR, microRNA; NC, negative control; OD, optical density.

A

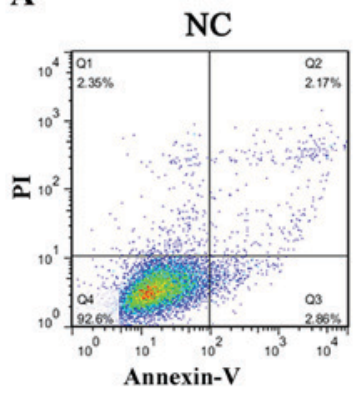

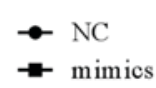

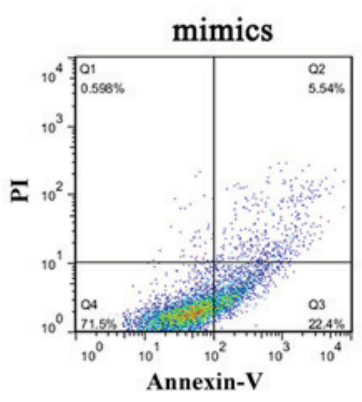

B

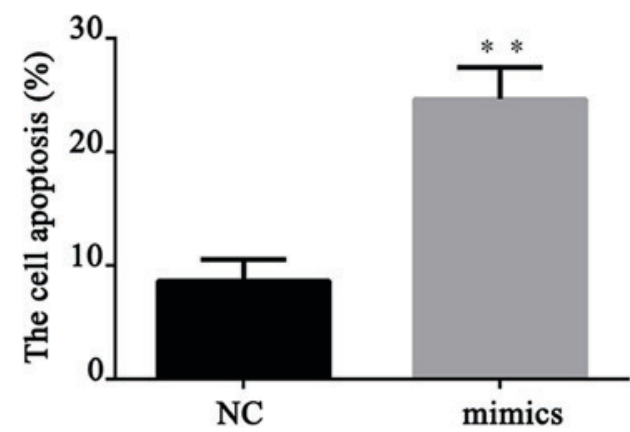

Figure 4. miR-671-5p induces gastric cancer cell apoptosis. A total of $24 \mathrm{~h}$ after MKN28 cells were transfected with miR-671-5p mimics or its NC, flow cytometry was performed to detect the cell apoptosis rate. (A) Flow cytometry results following staining in NC and mimic group. (B) Cell apoptosis rate in NC and mimic group. ${ }^{* *} \mathrm{P}<0.01$ vs. NC. Tests were performed in triplicate. miR, microRNA; NC, negative control; FITC, fluorescein isothiocyanate.

in the expression level of miR-671-5p compared with the level in the normal control $(\mathrm{NC})$ cells $(\mathrm{P}<0.01)$.

miR-671-5p inhibits gastric cancer cell proliferation. For cell proliferation detection, a CCK-8 kit was used according to the manufacturer's protocol. A total of $24 \mathrm{~h}$ after MKN28 cells were transfected with miR-671-5p mimics, it was demonstrated that miR-671-5p mimics significantly suppressed the proliferation ability of the MKN28 cells compared with the level in the NC cells, which was indicated by a slower increase of $\mathrm{OD}$ value $(\mathrm{P}<0.05$ at $48 \mathrm{~h}$ and $\mathrm{P}<0.01$ at $72 \mathrm{~h}$; Fig. 3$)$. These data indicate that miR-671-5p inhibits gastric cancer cell proliferation.

miR-671-5p induces gastric cancer cell apoptosis. A total of $24 \mathrm{~h}$ after transfection, FITC apoptosis detection was performed to measure the cell apoptosis level. As demonstrated in Fig. 4, compared with the NC, upregulation of miR-671-5p significantly increased the cell apoptosis rate of MKN28 cells $(\mathrm{P}<0.01)$. This indicated that miR-671-5p could induce gastric cancer cell apoptosis. To further explore the mechanism of the effect of miR-671-5p on cell apoptosis, the expression levels of cell apoptosis-related proteins (Bcl-2 and Bax) and corresponding mRNA levels were measured by western blotting and RT-qPCR. It was demonstrated that the ratio of $\mathrm{Bcl}-2 / \mathrm{Bax}$ significantly decreased when miR-671-5p was upregulated in MKN28 cells, with the expression levels of Bcl-2 being significantly decreased and the levels of Bax being significantly increased in the mimic group compared with the levels in the NC group $(\mathrm{P}<0.01$; Fig. 5). Taken together, these data suggest that miR-671-5p induces gastric cancer cell apoptosis via regulating the $\mathrm{Bcl}-2 / \mathrm{Bax}$ ratio.

URGCP is a direct target of miR-671-5p. To reveal the mechanism of miR-671-5p function in gastric cancer, its target gene was predicted using TargetScan and MiRanda databases (Fig. 6A). Luciferase reporter gene assay and western blot analysis were performed to confirm our prediction (Figs. 5C and 6B). The results indicated that the luciferase activity was significantly declined $(\mathrm{P}<0.01)$ in the $293 \mathrm{~T}$ cells co-transfected with miR-671-5p and miR-671-5p-URGCP-WT, compared with the NC; however, co-transfection with miR-671-5p and miR-671-5p-URGCP-MUT did not significantly affect the luciferase activity level (Fig. 6B). Additionally, the western blotting results suggested that miR-671-5p mimics markedly decreased URGCP protein expression levels compared with the level in the NC cells (Fig. 5C). These data demonstrate that miR-671-5p inhibits the expression of transcripts containing a miR-671-5p binding site and that URGCP is a direct target of miR-671-5p. 

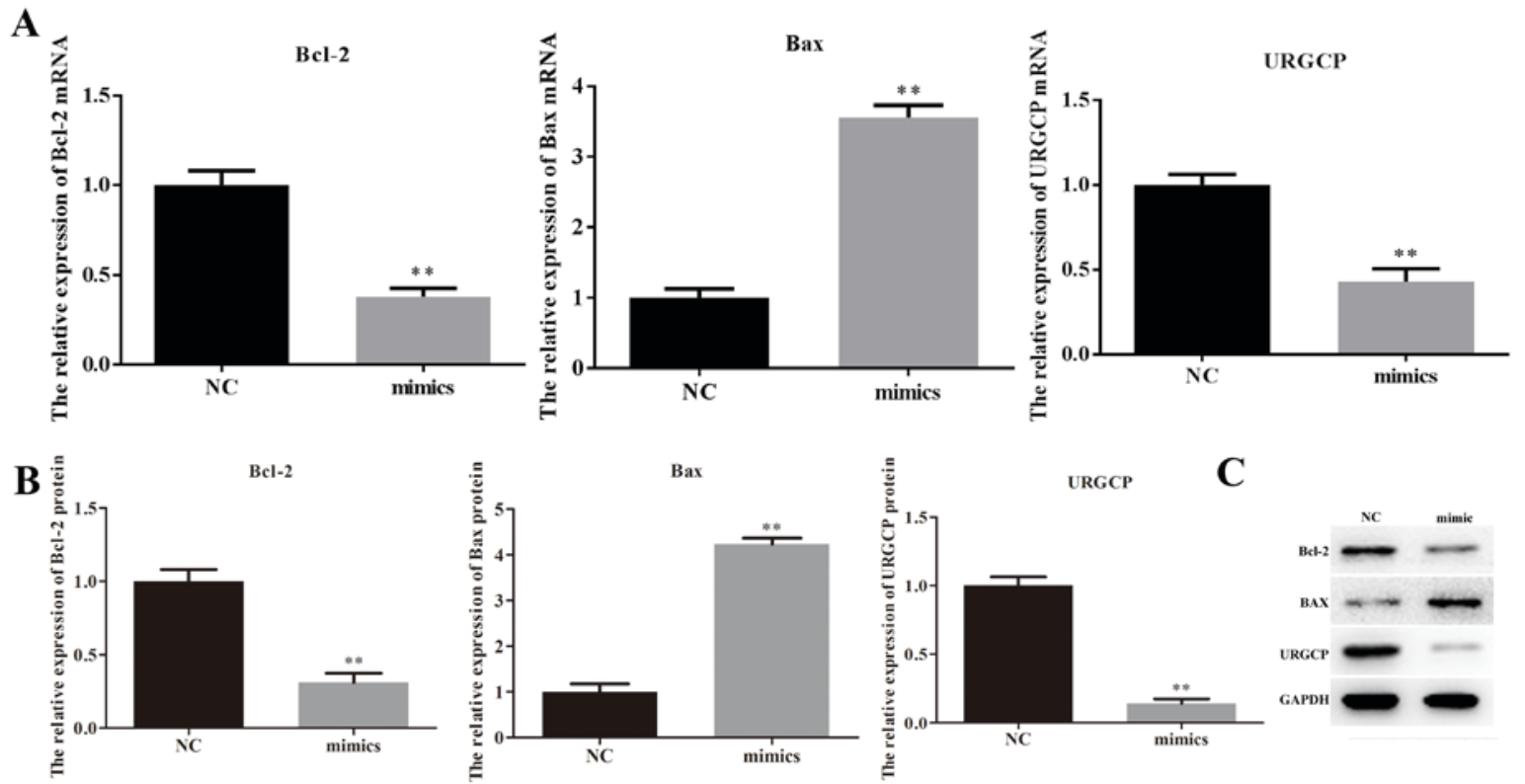

Figure 5. miR-671-5p affects the protein expression of Bcl-2, Bax and URGCP. A total of $24 \mathrm{~h}$ after MKN28 cells were transfected with miR-671-5p mimics or its $\mathrm{NC}$, reverse transcription-quantitative polymerase chain reaction and western blotting were performed to detect the mRNA and protein expression levels of Bcl-2, Bax and URGCP. (A) mRNA expression levels of Bcl-2, Bax and URGCP. (B) Relative protein expression levels of Bcl-2, Bax and URGCP. (C) Western blotting results of $\mathrm{Bcl}-2$, Bax and URGCP expression, with GAPDH as the internal reference. ${ }^{* *} \mathrm{P}<0.01$ vs. NC. miR, microRNA; NC, negative control; Bcl-2, B-cell lymphoma 2; Bax, B-cell lymphoma 2-asssociated X protein; URGCP, upregulator of cell proliferation.

A

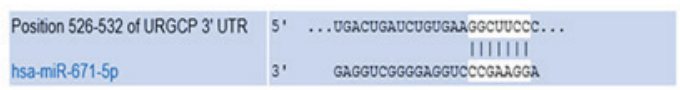

B

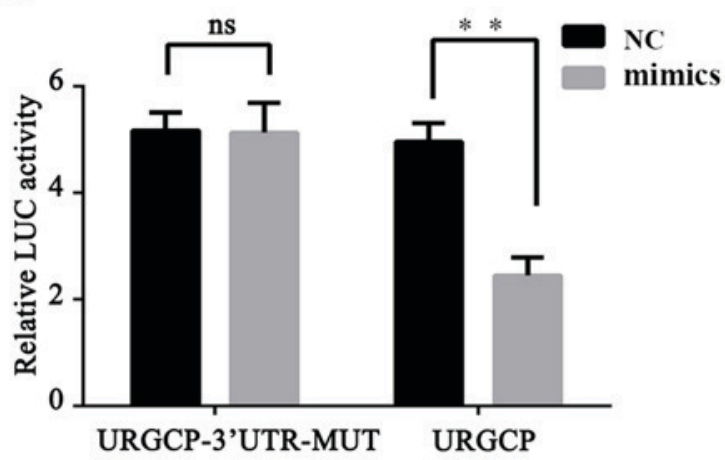

Figure 6. miR-671-5p directly targets URGCP. (A) Interaction between miR-671-5p and the 3'UTR of URGCP was predicted using TargetScan and MiRanda databases. (B) LUC activity of a reporter containing a wild-type URGCP 3'UTR or a MUT URGCP 3'UTR. URGCP-3'UTR-MUT indicates the URGCP 3'UTR with a mutation in the miR-671-5p binding site. ${ }^{* *} \mathrm{P}<0.01$ as indicated. miR, microRNA; NC, negative control; URGCP, upregulator of cell proliferation; UTR, untranslated region; LUC, luciferase; MUT, mutant; ns, not significant.

\section{Discussion}

A large amount of evidence has indicated that miRNA serve important roles in the development of several types of human cancer, such as gastric cancer $(29,30)$. Previous research has revealed that miR-671-5p has critical roles in human cancer progression. A study by Barbagallo et al (31) reported that miR-671-5p is involved in the development of glioblastoma multiform. A study by Tan et al (32) suggested that miR-671-5p functions as a tumor suppressor in breast cancer by targeting forkhead box M1. miR-671-5p has also been demonstrated to participate in epithelioid sarcoma via the regulation of SMARCB1 expression (33). However, the roles and underlying mechanisms of miR-671-5p in gastric cancer remain unclear.

In the present study, it was demonstrated that miR-671-5p expression was significantly decreased in gastric cancer MKN28 cells compared with the normal gastric HFE145 cells. The exact role of miR-671-5p in gastric cancer progression was further investigated and its underlying mechanisms explored. The present results suggested that overexpression of miR-671-5p in MKN28 cells inhibited cell proliferation and induced cell apoptosis. These results indicated that miR-671-5p functions as a tumor suppressor in gastric cancer by inhibiting cell proliferation ability and inducing cell apoptosis.

URGCP/URG4, an upregulator of cell proliferation, is upregulated in a variety of types of human cancer, including hepatocellular carcinoma, epithelial ovarian cancer, osteosarcoma and gastric cancer (19-22). URGCP functions as a tumor promoter, and it has been reported to serve critical roles in gastric cancer cell proliferation (22). In the present study, it was demonstrated that URGCP was a downstream target of miR-671-5p in human gastric cancer cells. TargetScan and MiRanda database results suggested that the 3 'UTR of URGCP contained the complementary sequence of miR-671-5p. Subsequently, the dual-luciferase reporter assay results indicated that miR-671-5p directly targeted URGCP. Furthermore, overexpression of miR-671-5p significantly reduced the expression level of URGCP. Thus, the present study successfully demonstrated that URGCP is a direct functional target of miR-671-5p in gastric cancer cells.

However, the present study only performed experiments involving the impact of miR-671-5p on gastric cancer cells. 
The pitfall of the present experiment was that the effect of miR-671-5p on normal gastric cell lines was not studied. Therefore, future research on the effects of miR-671-5pin normal gastric cells is required. As miR-671-5p was downregulated in gastric cancer cells, an miR-671-5p inhibitor should be added to normal gastric cancer cells to further determine the mechanism of miR-671-5p in gastric cells.

In summary, the present study demonstrated that miR-671-5p has a low expression level in gastric cancer cells. miR-671-5p may serve a role as a tumor suppressor in gastric cancer by inhibiting cell proliferation and inducing cell apoptosis via the direct regulation of URGCP. Therefore, the present data indicated that miR-671-5p may act as a novel therapeutic target in gastric cancer.

\section{Acknowledgements}

The authors would like to thank Wujin Hospital affiliated to Jiangsu University (Changzhou, China) for its financial and material support, as well as the supply of equipment.

\section{References}

1. Jemal A, Bray F, Center MM, Ferlay J, Ward E and Forman D: Global cancer statistics. CA Cancer J Clin 61: 69-90, 2011.

2. Ferro A, Peleteiro B, Malvezzi M, Bosetti C, Bertuccio P, Levi F, Negri E, La Vecchia C and Lunet N: Worldwide trends in gastric cancer mortality (1980-2011), with predictions to 2015, and incidence by subtype. Eur J Cancer 50: 1330-1344, 2014.

3. Torre LA, Bray F, Siegel RL, Ferlay J, Lortet-Tieulent J and Jemal A: Global cancer statistics, 2012. CA Cancer J Clin 65 87-108, 2015

4. Guggenheim DE and Shah MA: Gastric cancer epidemiology and risk factors. J Surg Oncol 107: 230-236, 2013.

5. Coburn NG: Lymph nodes and gastric cancer. J Surg Oncol 99: 199-206, 2009.

6. Shi Y and Zhou Y: The role of surgery in the treatment of gastric cancer. J Surg Oncol 101: 687-692, 2010.

7. Orditura M, Galizia G, Sforza V, Gambardella V, Fabozzi A, Laterza MM, Andreozzi F, Ventriglia J, Savastano B, Mabilia A, et al: Treatment of gastric cancer. World J Gastroenterol 20: 1635-1649, 2014.

8. Kelley JR and Duggan JM: Gastric cancer epidemiology and risk factors. J Clin Epidemiol 56: 1-9, 2003.

9. Hu Q, Sun W, Wang C and Gu Z: Recent advances of cocktail chemotherapy by combination drug delivery systems. Adv Drug Deliv Rev 98: 19-34, 2016.

10. Zhang H: Apatinib for molecular targeted therapy in tumor. Drug Des Devel Ther 9: 6075-6081, 2015.

11. Bartel DP: MicroRNAs: Genomics, biogenesis, mechanism, and function. Cell 116: 281-297, 2004

12. Bartel DP: MicroRNAs: Target recognition and regulatory functions. Cell 136: 215-233, 2009.

13. Mendell JT: MicroRNAs: Critical regulators of development, cellular physiology and malignancy. Cell Cycle 4: 1179-1184, 2005.

14. Jansson MD and Lund AH: MicroRNA and cancer. Mol Oncol 6: 590-610, 2012.

15. Chang S, He S, Qiu G, Lu J, Wang J, Liu J, Fan L, Zhao W and Che X: MicroRNA-125b promotes invasion and metastasis of gastric cancer by targeting STARD13 and NEU1. Tumour Biol 37: 12141-12151, 2016.

16. Yu B, Lv X, Su L, Li J, Yu Y, Gu Q, Yan M, Zhu Z and Liu B: MiR-148a functions as a tumor suppressor by targeting CCK-BR via inactivating STAT3 and Akt in human gastric cancer. PLoS One 11: e0158961, 2016.
17. Yin G, Zhou H, Xue Y, Yao B and Zhao W: MicroRNA-340 promotes the tumor growth of human gastric cancer by inhibiting cyclin G2. Oncol Rep 36: 1111-1118, 2016.

18. Cai J, Li R, Xu X, Zhang L, Wu S, Yang T, Fang L, Wu J, Zhu X, $\mathrm{Li} \mathrm{M}$ and Huang Y: URGCP promotes non-small cell lung cancer invasiveness by activating the NF-кB-MMP-9 pathway. Oncotarget 6: 36489-36504, 2015.

19. Papp G, Krausz T, Stricker TP, Szendrői M and Sápi Z: SMARCB1 expression in epithelioid sarcoma is regulated by miR-206, miR-381, and miR-671-5p on both mRNA and protein levels. Genes Chromosomes Cancer 53: 168-176, 2014.

20. Xie C, Song LB, Wu JH, Li J, Yun JP, Lai JM, Xie DY, Lin BL, Yuan YF, Li M and Gao ZL: Upregulator of cell proliferation predicts poor prognosis in hepatocellular carcinoma and contributes to hepatocarcinogenesis by downregulating FOXO3a. PLoS One 7: e40607, 2012.

21. Li WP and Zhou N: URG4 upregulation is associated with tumor growth and poor survival in epithelial ovarian cancer. Arch Gynecol Obstet 286: 209-215, 2012.

22. Huang J, Zhu B, Lu L, Lian Z, Wang Y, Yang X, Satiroglu-Tufan NL, Liu J and Luo Z: The expression of novel gene URG4 in osteosarcoma: Correlation with patients' prognosis. Pathology 41: 149-154, 2009.

23. Bossel Ben-Moshe N, Avraham R, Kedmi M, Zeisel A, Yitzhaky A, Yarden Y and Domany E: Context-specific microRNA analysis: Identification of functional microRNAs and their mRNA targets. Nucleic Acids Res 40: 10614-10627, 2012.

24. Zhang X, Peng Y, Jin Z, Huang W, Cheng Y, Liu Y, Feng X, Yang $M$, Huang $Y$, Zhao Z, et al: Integrated miRNA profiling and bioinformatics analyses reveal potential causative miRNAs in gastric adenocarcinoma. Oncotarget 6: 32878-32889, 2015

25. Song J, Xie H, Lian Z, Yang G, Du R, Du Y, Zou X, Jin H, Gao J, Liu J and Fan D: Enhanced cell survival of gastric cancer cells by a novel gene URG4. Neoplasia 8: 995-1002, 2006.

26. Marano L, Boccardi V, Braccio B, Esposito G, Grassia M, Petrillo M, Pezzella M, Porfidia R, Reda G, Romano A, et al: Comparison of the 6th and 7th editions of the AJCC/UICC TNM staging system for gastric cancer focusing on the ' $\mathrm{N}$ ' parameter-related survival: The monoinstitutional NodUs Italian study. World J Surg Oncol 13: 215, 2015.

27. Capes-Davis A, Theodosopoulos G, Atkin I, Drexler HG, Kohara A, MacLeod RA, Masters JR, Nakamura Y, Reid YA, Reddel RR and Freshney RI: Check your cultures A list of cross-contaminated or misidentified cell lines. Int J Cancer 127: $1-8,2010$.

28. Livak KJ and Schmittgen TD: Analysis of relative gene expression data using real-time quantitative PCR and the 2(-Delta Delta C(T)) method. Methods 25: 402-408, 2001.

29. Calin GA and Croce CM: MicroRNA signatures in human cancers. Nat Rev Cancer 6: 857-866, 2006.

30. Petrocca F, Pilozzi E, Rapazzotti M, Aurello, P, Mercantini P, Volinia S, Ruco L, Croce CM and Vecchione A: MicroRNAs deregulation in gastric cancer. Cancer Res 66: 1338, 2006.

31. Barbagallo D, Condorelli A, Ragusa M, Salito L, Sammito M, Banelli B, Caltabiano R, Barbagallo G, Zappalà A, Battaglia R, et al: Dysregulated miR-671-5p/CDR1-AS/ CDR1/VSNL1 axis is involved in glioblastoma multiforme. Oncotarget 7: 4746-4759, 2016.

32. Tan X, Fu Y, Chen L, Lee W, Lai Y, Rezaei K, Tabbara S, Latham P, Teal CB, Man YG, et al: miR-671-5p inhibits epithelial-to-mesenchymal transition by downregulating FOXM1 expression in breast cancer. Oncotarget 7: 293-307, 2016.

33. Song J, Xie H, Lian Z, Yang G, Du R, Du Y, Zou X, Jin H, Gao J, Liu J and Fan D: Enhanced cell survival of gastric cancer cells by a novel gene URG4. Neoplasia 8: 995-1002, 2006. 